University of Wollongong

Research Online

Faculty of Business - Papers (Archive)

Faculty of Business and Law

$1-1-2014$

Back translation: an emerging sophisticated cyber strategy to subvert advances in 'digital age' plagiarism detection and prevention

Michael Jones

University of Wollongong,mjones@uow.edu.au

Lynnaire Sheridan

University of Wollongong, lynnaire.sheridan@otago.ac.nz

Follow this and additional works at: https://ro.uow.edu.au/buspapers

Part of the Business Commons

Research Online is the open access institutional repository for the University of Wollongong. For further information contact the UOW Library: research-pubs@uow.edu.au 


\title{
Back translation: an emerging sophisticated cyber strategy to subvert advances in 'digital age' plagiarism detection and prevention
}

\begin{abstract}
Advances have been made in detecting and deterring the student plagiarism that has accompanied the uptake and development of the internet. Many authors from the late 1990s onwards grappled with plagiarism in the digital age, presenting articles that were provoking and established the foundation for strategies to address cyber plagiarism, including software such as Turnitin. In the spirit of its predecessors, this article presents a new, less-detectable method of cyber-facilitated plagiarism known as 'back translation', where students are running text through language translation software to disguise the original source. This paper discusses how this plagiarism strategy attempts to subvert academic attempts to detect plagiarism and maintain academic integrity in the digital age, before presenting useful detection tools and then critiquing three classroom plagiarism management approaches for their usefulness in the current digital and educational context.
\end{abstract}

\section{Keywords}

digital, age, plagiarism, detection, sophisticated, prevention, back, translation, strategy, emerging, cyber, subvert, advances

\section{Disciplines \\ Business}

\section{Publication Details}

Jones, M. \& Sheridan, L. (2015). Back translation: an emerging sophisticated cyber strategy to subvert advances in 'digital age' plagiarism detection and prevention. Assessment and Evaluation in Higher Education, 40 (5), 712-724. 


\section{Back Translation: An Emerging Sophisticated Cyber Strategy to}

Subvert Advances in 'Digital Age' Plagiarism Detection and

\section{Prevention}

Michael Jones and Lynnaire Sheridan

School of Management, Operations and Marketing, Faculty of Business University of Wollongong, Wollongong, New South Wales 2522, Australia 


\title{
Back Translation: An Emerging Sophisticated Cyber Strategy to Subvert Advances in 'Digital Age' Plagiarism Detection and Prevention
}

\begin{abstract}
Advances have been made in detecting and deterring the student plagiarism that has accompanied the uptake and development of the internet. Many authors from the late 1990s onwards grappled with plagiarism in the digital age, presenting articles that were provoking and established the foundation for strategies to address cyber plagiarism, including software such as Turnitin ${ }^{\mathrm{TM}}$. In the spirit of its predecessors, this article presents a new, less-detectable, method of cyberfacilitated plagiarism known as 'back translation' where students are running text through language translation software to disguise the original source. This paper discusses how this plagiarism strategy attempts to subvert academic attempts to detect plagiarism and maintain academic integrity in the digital age before presenting useful detection tools and then critiquing three classroom plagiarism management approaches for their usefulness in the current digital and educational context.
\end{abstract}

Keywords: plagiarism; assessment design; Academic integrity; Back Translation; student equity

\section{Why has Plagiarism Flourished in the Digital Age?}

The concept of plagiarism is not a modern phenomenon. It has been practiced for as long as the art of writing itself has. Shakespeare seems to have misappropriated text as others have misappropriated from him (Julius 1998; Thomas 2000). Writers such as Newton, Leibniz and Calculus have also been accused of plagiarism (Heather 2010). Writers and poets in $16^{\text {th }}$ century England were lamenting their loss of ownership as the rights to their work passed from author to agent upon completion (Sutherland-Smith 2010). This began a bevy of copyright suits and laws until ownership of text became more certain in the mid- $18^{\text {th }}$ century (Park 2003).

The term plagiarism derives from the Latin plagiarus meaning 'kidnapper' (Walker 1998). This was built into English law in 1710 where the product of the author was regarded as the author's 'child'. In misappropriating an author's text the offender 
was seen as kidnapping the words and ideas from the originator (Sutherland-Smith 2010).

The nature of plagiarism has changed since the arrival of the digital age. Plagiarism was once a difficult and time-consuming enterprise which tended to focus on acquiring material from print-based sources (Carroll 2002; Lea and Jones 2010). This misappropriation of text required real effort and its poor return on investment promoted greater honesty (Ellery 2008). Now, armed with an abundance of electronic journals and literary information on the internet (Bennett 2005), it is only too easy for honest and dishonest students alike to find, copy, and paste, relevant text into their own academic submissions (Simon et al. 2004).

Today, we are dealing with what Barbrook (2002) labels the 'Napster generation' (279). To put this into perspective, if students feel no qualms in downloading (or pirating) movies and music, and not seeing legal and cultural deterrents to the practice, what imperatives are in place for them to treat text any differently? Culwin (2006) and Mirow and Shore (1997) found that through the process of cutting and pasting from the web and changing a word here or there, students assume ownership and originality for the text they have borrowed. While this research is now quite old - given the current generation of web-savvy students - it is still relevant in regard to student beliefs of ownership. Other research finds that students consider that copying from the internet is less dishonest than taking text from books; that the internet is a free-zone, where copying is permitted; and that copying from the internet is harder to detect (Flowerdew and Li 2007).

To add to the increasingly liberal environments which are nurturing plagiarism, we now have internet sites where students can procure cheap papers or where they can be custom written to order (Bennett 2005; Selwyn 2008; McKeever 2006). Students can take information from blogs (Selwyn 2008) or can scan print material with hand-held scanners (Underwood and Szabo 2003. 'The range of dishonest practice is limited only by students’ abilities to use technology creatively.' (Underwood and Szabo 2003, 470).

The effect of these increased opportunities for cheating not only diminishes student academic labour; they also impact in student equity, and reduce reading, thinking, reflection, creativity and originality (Bennett 2005; Ellery 2008). Equity is a particularly problematic issue. When honest students discover they are competing with students who cheat, they feel compelled themselves to plagiarise to maintain a level 
playing field (Park 2004; Sutherland-Smith 2010; Underwood and Szabo 2003; Lancaster and Culwin 2007).

On the other side of this issue, the educators who enforce academic integrity are becoming increasingly reluctant to punish and intervene (Sharman and Wilshire 2007). This stems from several reasons, among these are the increased workload involved in detection and conviction; the stress and unpleasantness of pursuing a charge of plagiarism (de Jager and Brown 2010); the ethical dilemma based on the university's position as a provider of education, not as distributer of punishment (Ashworth, Bannister and Thorne 1997); the economic pressure on academics to maintain pass levels and enrolment numbers; the lack of bite within universities who maintain a rhetoric of 'plagiarise and be punished' but who are reluctant to follow through on their convictions usually due to a highly risk-averse position (Sharman and Wilshire 2007; Bennett 2005).

Student plagiarism is not only a problem that affects a large proportion of students, the problem is in fact growing: '[t]here is mounting evidence that student cheating in general, and plagiarism in particular, are becoming more common and more widespread.' (Park 2003, 471). Research by McCabe, Trevino, and Butterfield (2001), which looks at the growth in plagiarism over a period of 30 years found that student plagiarism is becoming increasingly problematic, leading Hart and Friesner $(2004,89)$ to find that: 'plagiarism may now be a serious and endemic problem'. The British newspaper 'The Telegraph' reported that 'More than 17,000 incidents of [serious] cheating were recorded by universities in the 2009-10 academic year' this represents an increase of 50\% over four years (Barrett 2011).

Re-visiting papers such as Austin and Brown's (1999) article specifically examining internet plagiarism and Duggan's (2006) editorial overview of plagiarism issues (emerging from a UK conference titled Prevention, Practice and Policy) in this same journal and subsequent discussions, it is clear that many of the issues they discussed continue to emerge in articles on plagiarism today but, in many aspects, there have been some advances and new strategies have been developed to combat internetfacilitated plagiarism such as Turnitin ${ }^{\mathrm{TM}}$ software. This said, in discovering the phenomenon of back translation (this is discussed below), it is clear that it is important to keep on top of emerging plagiarism and examine how students attempt to subvert the digital plagiarism prevention strategies that, increasingly, have been put in place from the early 2000s onwards. This discussion also provides an opportunity to see how 
evolving strategies, such as cross-language plagiarism detection software, might come to the fore in the coming years.

\section{Back Translation a New 'Cyber-Based' Form of Plagiarism}

The usual method by which students plagiarise is for the student to copy a section of text, from a journal article for instance. They then paste this into their own work, asserting that the completed collage of blended writing is their own authentic creation. The degree of plagiarism that might apply, in cases such as this, differs according to the proportion of text which has been 'borrowed', by the amount of 'paraphrasing' or word altering that has occurred, and by the degree of referencing the student has included acknowledging original ownership.

Discovering this common form of plagiarism is reasonably simple. However, it is not fool-proof. Students usually leave signposts and indicators which draw the examiner's attention. These indicators include: inconsistencies in style; font; sentence structure; dates of sources or material within the text; spelling styles (American and English), and in students' writing abilities (Carroll 2002). Students' argument can be off subject, referring to aspects which digress from the desired objective or do not address the requirements of the assessment. Harris (2001) finds that the structure and density of the sentences within the student's work may also reveal the likelihood of plagiarism, the greater the variation in sentence length, the more probable it is that plagiarism has occurred. He states that:

\footnotetext{
'Software analysis of student essays shows that college freshmen usually have an average sentence length of about 15 to 17 words ... As writers improve, sentence structures tend to grow more complex and hence sentence lengths increase. (Note that there are exceptions such as business prose and journalese, which set short sentences as a goal.) Generally, however, if the sentences of an entire paper or a section of a paper are unusually long you may want to give the paper a second look for other clues to copying. Finally, if the sentences vary in average length by paragraph, that is also cause for concern’. (69-70)
}

A more recent development in techniques for student plagiarism - especially for those attending English-speaking institutions from non-English speaking backgrounds - is to make use of the advanced technologies now available on the internet to translate the text they cut-and-paste in the hope that their cheating will be completely disguised. With 
tools such as (Babelfish or Google for instance) students can easily convert the English language text that they have copied to a different language (Spanish for example) and then retranslate these converted words back into English.

An example of how this works can be seen below. In this example a very famous passage of text taken from Dr. Martin Luther King Jr (2004) has been selected. The authors then translated this text into Spanish through Babelfish (http://babelfish.yahoo.com/):

English Original:

'I have a dream that one day this nation will rise up and live out the true meaning of its creed: 'We hold these truths to be self-evident, that all men are created equal'.(1)

Spanish Translation:

Tengo un sueño que un día esta nación se alzará y vivirá hacia fuera el significado verdadero de su credo: 'Llevamos a cabo estas verdades para ser evidentes en sí, ese todos los hombres somos equal.' creados;

Retranslation into English:

I am a sleepy that a day this nation will raise itself and live outside towards the true meaning of its creed: 'We carry out these truths to be evident in himself, those all the men we are equal'. Created;

It is clear from this illustration, since we are reasonable familiar with the original text from Dr. King, that this translation is flawed and somewhat preposterous. However, while we may argue its legibility, it would be hard to accuse this student of plagiarism. The text does not look like it has been copied. Instead it looks poorly written, and perhaps poorly understood.

If, however, we took a less notable segment of text and translated it similarly. We would find that the text becomes more difficult to spot for plagiarism and for fidelity. This is illustrated in the following passage taken from Williams (2005):

English Original: 
'While many universities around the world would probably claim that their publicly stated policies and procedures will act as a deterrent to any student contemplating plagiarism, their publication alone is unlikely to cut any sway with would-be plagiarists. In North America, however, the punitive systems in place to discredit plagiarists tend to be an integral part of university-wide honour codes that, effectively implemented, can make students think long and hard about engaging in plagiarism. These university 'honour codes' have a long history, and they are treated very seriously by the authorities. '(8)

\section{Spanish Translation:}

Mientras que muchas universidades en todo el mundo demandarían probablemente que sus políticas y procedimientos público indicados actuarán como impedimento a cualquier estudiante que comtempla plagio, su publicación solamente es poco probable cortar cualquier sacudimiento con los plagiarios supuestos. En Norteamérica, sin embargo, los sistemas punitivos en el lugar para desacreditar a plagiarios tienden a ser una parte integrante de los códigos universidad-anchos del honor que, aplicados con eficacia, pueden hacer que los estudiantes piensan largo y duro en el acoplamiento a plagio. Estos códigos del honor del `de la universidad tienen una larga historia, y son tratados muy seriamente por las autoridades.

\section{English Retranslation:}

Whereas many universities anywhere in the world would demand probably that their indicated policies and procedures public will act like impediment to any student who comtempla plagiarism, its publication is only little probable to cut any shaking with the supposed plagiarists. In North America, nevertheless, the punitive systems in the place to discredit plagiarists tend to be an integral part of the university-wide codes of the honor that, applied with effectiveness, can do that the students think length and it last in the connection to plagiarism. These codes of the honor of `of the university have one long history, and are treated very seriously by the authorities.

English Retranslation (after applying a spellchecker - including grammar):

Whereas many universities anywhere in the world would demand probably that their indicated policies and procedures public will act like impediment to any student who contemplate plagiarism, its publication is only little probable to cut 
any shaking with the supposed plagiarists. In North America, nevertheless, the punitive systems in the place to discredit plagiarists tend to be an integral part of the university-wide codes of the honour that, applied with effectiveness, can do that the students think length and it last in the connection to plagiarism. These codes of the honour of the university have one long history, and are treated very seriously by the authorities.

A student who has submitted a passage similar to that would be seen as having poor English language skills, and the passage or paper would be dismissed accordingly. It is also likely that the person marking the essay will expend time and energy correcting this student's grammar. It is unlikely the examiner would assume that the passage was entirely plagiarised, with little, if any, student input - which is entirely the case here.

Given the likelihood that students in an increasingly internationalised tertiary education setting may trade on their poor English skills as a reason for the paper's lack of coherence, and that examiners may likewise consider that poor writing quality has resulted from the writer's poor grasp of the language, detection of plagiarism in such cases is not as simple as it is for more typical forms of plagiarism.

\section{Back Translation Subverts Existing Plagiarism Prevention}

Back in 1999, Austin and Brown suggested that papers could be evaluated for digital plagiarism via general sight evaluation (analysis of writing style) then suspicious texts could be further investigated using digital technology ranging from searching the sources that might have been used by students through to starting to use the then emerging plagiarism detection software (predecessors to Turnitin ${ }^{\mathrm{TM}}$ ).

We will now demonstrate how back translation has subverted initial detection as well as the advanced plagiarism detection software that is now in common use.

\section{Back translation impedes analysis of writing style}

Even in approaches to detected off-line plagiarism, instinctual or formal analysis of writing style has proved useful to tertiary educators. As argued above, one of the key strategies of back translation is to confuse the reader by disguising plagiarism as a language competency issue. With increasing numbers of international English as a Second Language (ESL) students attending English speaking institutions (Hurst 2013; Coughlan 2011), there has never been a better time perhaps to use this ruse. 


\section{Back translation thwarts Turnitin ${ }^{T M}$}

A common tool employed for the detection of plagiarism, a targeted response to the misuse of digital content, is Turnitin ${ }^{\mathrm{TM}}$ (turnitin.com). This tool provides a content matching function to rate student papers on their proportion of originality. When Turnitin $^{\mathrm{TM}}$ was compared with manual detection of plagiarism the average examiner missed four of five occurrences of plagiarism which were subsequently identified by Turnitin $^{\mathrm{TM}}$, (Jocoy and DiBase 2006). This, and similar findings, have inspired the uptake of automated plagiarism detection software in academic institutions worldwide.

The increasing use of automated plagiarism detection means that students who engage in deliberate plagiarism have had to develop new strategies to make their plagiarism difficult to detect. A study of first-year business students by Koshy (2008) found that students would deliberately misspell words when submitting documents to Turnitin $^{\mathrm{TM}}$ to avoid text matching detection. In fact, $11 \%$ of her participants agreed with the statement 'It is more important to avoid text matching than plagiarism' (Koshy 2008, 8).

The emergence of back translation is yet another response to students' understanding that current software is designed to match text used in assessments word for word with external sources. Back translation subverts detection software by changing the words but keeping the essence of the concept. It cleverly conceals the source as detectable elements of the original text are literally 'lost in translation'. Furthermore, when back translation is used by students from an ESL background, the grammatical errors are expected and somewhat permissible thus adding to the subterfuge. The challenge then often becomes ‘certifying the absence of plagiarism', as (Evans 2006, 87) describes it.

\section{Existing and Emergent Strategies to Detect Back Translation}

By acknowledging the existence of back translation, rather than perceiving it as an English language issue, it is possible (even with existing tools and technologies) to detect it via proactive analysis of writing style and observing the development of writing. In the future, evolving cross language tools may lead to a Turnitin ${ }^{\mathrm{TM}}$ multilanguage equivalent or yet more sophisticated tools to detect plagiarism including the use of back translation. Each of these strategies will now be explained. 


\section{Analysis of writing style}

It is presented here that proactive analysis of writing style can include deliberate collection of student writing samples as a point of reference for future assessable work or using intrinsic analysis software.

\section{Sampling writing styles}

While the most basic approach to writing style analysis may be considered lowtech and old fashioned, in 1999 Carnevale in "The Chronicle for Higher Education” proposed the collection of samples of a student's natural writing style for future comparison with subsequently submitted assessments to detect plagiarism. This is still pertinent today to back-translation.

As back-translation might appear to be simply poor writing, the concept of collecting samples of a student's writing at the beginning of a course does seem to be a useful way to develop a point of reference for confirming or dismissing plagiarism in assessments where back-translation has been used, as a student's actual abilities can be compared to the assessment language and style.

If this approach were adopted, the authors of this paper further suggest that the written sample of work could be spontaneously announced and collected in class. It could be a non-assessable piece of work with loose time limits perhaps summarising the first few weeks of class' topics. The document would contain the student's natural grammatical style and language level as there would be no opportunity for external input or back-translation. It would be an authentic piece of work with which to compare future assessment tasks.

This said comparing style manually and within a group assignment setting would still be time consuming, but if treated as a reference for benchmarking questionable student submissions, it would be viable.

\section{Intrinsic analysis software}

Most automated plagiarism detection software (including Turnitin ${ }^{\mathrm{TM}}$ ) currently uses extrinsic analysis, that is, 'finding near-matches to a text in a database of texts' (Stamatatos and Koppel 2011, 2). The alternative is intrinsic detection. This method focuses on writing style, and strives to determine whether the text was generated by 
multiple authors, rather than the single student author who is claiming the work is authentic (Stamatatos and Koppel 2011).

For detection, Carnivale (1999) referred to software designed to determine the authentic authorship of work based on writing style so, potentially, labour intensive manual comparisons of written documents may not be necessary. Maurer and Zaka (2007) refer to a similar software tool called Cloze. Traditionally the term 'cloze' is associated with language comprehension activities that require students to fill in blanks in a text using words that satisfactorily complete the meaning. In this case, the student's original work is turned into a cloze passage text with every fifth word removed before requiring the same student to fill back in the missing words. This can test whether the student produced the work because, according to Maurer and Zaka (2007)

it has been proven through hundreds of experiments that a person that has written the document will fill in words more than $80 \%$ correctly, while persons who have not written the text will not manage more than some $50 \%$ correct fill-ins at most! (2).

Whether it would be appropriate to apply such a Cloze test to all students, or just suspicious cases, is not clear in terms of its labour intensiveness and perceptions of equity or victimization.

\section{Observation of text development}

Austin and Brown (1999) suggested that students exhibit writing to teachers as it develops, today the authors propose that a less labour intensive and intrusive method is now possible. Might the use of the tracking elements of wikis, for example, aid in plagiarism detection both in single and multiple student authored assessments?

Wikis

Weingarten and Frost $(2011,52)$ explain ' ...wikis add a dimension of meta-analysis to the activity: on most wiki platforms, contributions and edits are logged, so that the history of the process that produced the text can be retraced and examined'. The authors propose that the use of wikis for student assessment development might illustrate examples of cutting or pasting into the document as well as whole paragraphs of poorly written materials (potentially back-translated) suddenly appearing in blocks. When a 
document does not appear to be being written, but instead, pasted in chunks, further evidence of originality could be requested from the student.

Also, back-translation in group work may become identifiable. Currently it is possible that an unsuspecting group member might edit out flaws in back-translated text by correcting back-translated text, which was simply perceived as work of poor quality, in the production of a polished final draft of an assessment. A wiki would monitor the arrival and editing of that text into the assessment. How labour intensive wiki monitoring might be is unclear.

\section{Cross Language plagiarism detection software}

To match student ingenuity, there have also been further technological advances in the development of tools much more closely aligned with attacking the cross-language element of back translation. Beyond tools designed for English, cross-language plagiarism detection is a growing area of research fundamentally focused on how to compare documents across different languages (Ceska, Toman, and Jezek 2008, 83).

Ceska, Toman, and Jezek $(2008,84)$ developed a software model designed to detect plagiarism across languages even where some words were replaced in the final plagiarised text with synonyms. They achieved this by creating a multilingual database of words which could match synonyms across European languages; text matching could then take place independent of the language. It was important to '...choose such features that can be employed in most of languages regardless of the grammatical rules they apply’ (Ceska, Toman, and Jezek 2008, 86). Using Czech and English as a starting point, they found that their model across languages had no negative impact on the accuracy of plagiarism detection.

These sophisticated models may hold the key to detecting multilingual plagiarism including back-translation but, as at 2011, 'cross-language plagiarism is an important direction of plagiarism detection research but is still in its infancy' (Potthast et al. 2011, 59). It is important to note that the cross-language software has not been specifically targeted to address back-translation. In many cases it has emerged as a response to a debate in translation literature where there are concerns about whole pieces of work being translated into a new language with no acknowledgement of the original author of the work. Whilst there is also some discussion of 'translation plagiarism', defined by Kent and Salim (2009) as 'translation of a sentence in the source language in the way that ends up using almost the exact same words as the original 
source used by the original author' (Kent and Salim 2009, 39), this is still quite different from our back-translation scenario where the text is 'laundered' through internet translation software rather than being an unintentional translation back to the original language. Back-translation, however, obviously stands to benefit from this technology.

While these ideas have been proffered, overall, back-translation and its detection are rarely touched on in the literature thus much more empirical research needs to be undertaken on this plagiarism strategy and its potential detection.

The section above has discussed the vast field measures that can be used to detect plagiarism and, in particular, plagiarism that has resulted through backtranslation. This next section will focus on managing plagiarism rather than just its detection, and will elaborate on a number of techniques which can be adopted by teachers and examiners to defeat the potential for plagiarism even by avoiding it all together.

\section{Philosophical Approaches to Classroom Management of Plagiarism}

Accepting that back-translation exists, the authors consider it important to re-visit the overarching approaches to classroom-level plagiarism management and their relevance to the current educational and digital context.

It is acknowledged that plagiarism needs to be institutionally managed, as part of sustaining academic integrity, and that classroom educators do not control the entire framework from policy to punishment. If preventing plagiarism is the creation of '... an environment where, regardless of the motivation, the chances of detection and punishment are uncomfortably high’ (Williams 2005, 8), individual classroom teachers actually cannot prevent plagiarism. Instead, it is presented here that they can choose to work with plagiarism (embrace it), deter it or avoid it.

\section{Embrace plagiarism: Legalise it for learning purposes}

This takes a 'legalise' rather than 'criminalise' approach and has emerged very much as a response to the digital environment and its current real-world use. Jones (2009) refers to increasing calls for academics to embrace a new world where copying of text is not considered plagiarism. Her commentary was based on the book "Free Culture" by Lessig who does believe in acknowledgement that facilitates rather than inhibits creativity, advancement and, by default, learning (Lessig 2004). 
Whilst the authors are not comfortable to endorse a carte blanche approach, it is understood that if plagiarism became an authorised student activity, it could be used specifically to achieve student learning goals.

\section{Deter plagiarism: Teach morality and garner good academic conduct}

Philosophically, deterring plagiarism is ‘...the creation of a (perhaps, Utopian)

environment where students never feel motivated to plagiarise' (Williams 2005, 8).

Educating students on issues associated with academic integrity, including plagiarism, and engaging them in the process of establishing codes of conduct or abiding by an institution's honour code is purported as a means of creating such an environment (Jones 2009). Ideally it creates a student culture that will not tolerate plagiarism and, where this fails, punishment of offenders is severe acting as a deterrent to others (Williams 2005).

The premise for this approach is that, while many strategies can be put into place to maintain academic integrity striving to rule out plagiarism, there may always be new ways to cheat 'Trust and student honesty thus remain central to a successful academic system’ (Evans 2006, 87). This is a proactive approach aimed at broadly supporting academic integrity that remains relevant today.

\section{Avoid plagiarism: Design it out}

Good assessment design has long been considered a stalwart in plagiarism prevention. While myriads of assessment design techniques exist in the academic literature, we would like to present a higher level classification of the key approaches and their current relevance, particularly in light of back translation:

(1) Supervise

As plagiarism fundamentally cannot occur in an examination setting, a shift in assessment from written assignments to exams would prevent plagiarism (Jones 2009; Carnevale 1999). Although this would hold true for back-translation, it is often not a practical option.

(2) Personalise 
Davis (2011) suggests the personalisation of assignments. This means that the task relies upon the student's personal experience or perhaps data or information which is provided by the lecturer or generated by the students in an earlier phase of the work. The nature of the assessment means that it cannot be copied year to year or downloaded from any external sources. Sterngold (2004) similarly suggests that the assignment could be based on a guest lecturer or a site visit, again, unique events that preclude plagiarism.

\section{(3) Change}

Alter (slightly or extensively) assessment tasks for each student cohort to ensure that submission of an earlier piece of work for the same course would not meet the current assessment criteria (Harris 2001).

(4) Restrict

Provide students with a limited list of academic sources that they can use to complete the assessment task so only these may be used and cited. As the sources are well known to the teacher, students will understand that copying is futile (Harris 2001).

(5) Create

Focus assessment tasks on activities that are not usefully supported by plagiarism. Austin and Brown (1999) suggested that having students create rather than write would prevent plagiarism. The following assessment task provides an example of this technique: 'You are the founder of the world's first iron-ore plant on the moon. Explain the five most important steps you would put in place to ensure a safe working environment, and explain each in detail.' In this task the students must create their own logical work rules, and in so doing will contrive arguments to support these ideas.

(6) Formative

Addressing one root cause of plagiarism, Sterngold (2004) suggested that assessments be divided into portions rather than larger tasks. His rationale is that last minute time pressures associated with large assessments are conducive to 
plagiarism. By helping students to manage their time and breaking down tasks, and assessing these formatively, the reliance on plagiarism may be reduced.

Reflecting on all the recommendations of the digital plagiarism combatants of the late 1990s and early 2000s, and considering today's context, assessment design based upon techniques presented above has - in contrast to other strategies - remained relevant despite the enormous digital change in the last decade.

\section{Conclusion}

The emergence of back translation as a sophisticated cyber strategy demonstrates an attempt by some students to subvert advances in 'digital age' plagiarism detection and prevention. This paper has discussed strategies that will work to detect back translation but has also taken a look at classroom plagiarism management.

For plagiarism to be eradicated, if that were ever possible, approaches based on: embracing a culture of free thought; creating a moral student culture with honour codes; and, good assessment design that avoids plagiarism altogether may need to be part of comprehensive multipronged strategy. In acknowledging this, planning assessments with a view to designing out plagiarism will perhaps have the greatest potency towards countering back-translation, as an emerging form of plagiarism, and thus gives classroom academics a pragmatic strategy for dealing with it on a day to day basis, particularly as tools like TurnitinTM begin to show cracks and are no longer a deterrent to all students.

Indeed, as we move into what some are calling the post digital age 'The state of being in which you assume the digital instead of marvelling at it.’ (http://nextberlin.eu/2012/01/what-is-post-digital/), we suspect that designing out plagiarism via good assessment design will continue to stand steady while many other aspects of education change in light of continuing global change in the digital space. 


\section{References}

Ashworth, P., Bannister, P., and Thorne, P. 1997. "Guilty in whose eyes? University students' perceptions of cheating and plagiarism in academic work and assessment.” Studies in Higher Education 22 (2): 187-203.

Austin, J., and Brown, L. 1999. “Internet Plagiarism: Developing Strategies to Curb Student Academic Dishonesty.” The Internet and Higher Education 2 (1): 2133.

Barbrook, R. 2002. "The Napsterization Of Everything." Science as Culture 11 (2):277285. doi: 10.1080/09505430220137289.

Barrett, D. 2011. "The cheating epidemic at Britain's universities." The Telegraph.

Bennett, R. 2005. "Factors associated with student plagiarism in a post-1992 university." Assessment \& Evaluation in Higher Education 30 (2):137-162.

Carnevale, D. 1999. "Web Services Help Professors Detect Plagarism." The Chronicles of Higher Education 46 (12):A49.

Carroll, J. 2002. A Handbook for Deterring Plagiarism in Higher Education. Oxford, UK: The Oxford Centre for Staff and Learning Development.

Ceska, Z., Toman, M., and Jezek, K. 2008. "Multilingual Plagarism Detection." In R. Dochev, R., M. Pistore, P.Traverso, eds. Artificial Intelligence: Methodology, Systems, and Applications. 13th International Conference, AIMSA 2008, Varna, Bulgaria, September 2008, Proceedings (83-92). Heidelberg, Berlin: Springer.

Coughlan, S. 2011, March 10. "Record numbers of international students." BBC News. Retrieved from http://www.bbc.com

Culwin, F. 2006. "An active introduction to academic misconduct and the measured demographics of misconduct." Assessment \& Evaluation in Higher Education 31 (2): 167-182.

Davis, L. 2011. "Arresting Student Plagarism: Are we investigators or educators?" Business Communication Quarterly 74: 160-163.

de Jager, K., and Brown, C. 2010. "The tangled web: investigating academics’ views of plagiarism at the University of Cape Town." Studies in higher education 35 (5):513-528. doi: 10.1080/03075070903222641.

Duggan, F. 2006. "Plagiarism: prevention, practice and policy." Assessment \& Evaluation in Higher Education 31 (2): 151-154. 
Ellery, K. 2008. "An investigation into electronic-source plagiarism in a first-year essay assignment." Assessment \& Evaluation in Higher Education 33 (6):607-617.

Evans, R. 2006. "Evaluating an electronic plagarism detection service." Active Learning in Higher Education 7 (1): 87-99.

Flowerdew, J., and Li, Y. 2007. "Plagiarism and Second Language Writing in an Electronic Age." Annual Review of Applied Linguistics 27:161-183.

Harris, R. 2001. "The plagiarism handbook: strategies for preventing and dealing with plagiarism." Los Angeles, CA: Pyrczac Publishing.

Hart, M., and Friesner, T. 2004. "Plagiarism and Poor Academic Practice - A Threat to the Extension of e-Learning in Higher Education?" Electronic Journal on eLearning 2 (1): 89-96.

Heather, J. 2010. "Turnitoff: identifying and fixing a hole in current plagiarism detection software." Assessment \& Evaluation in Higher Education 35 (6):647660.

Hurst, D. 2013, February 27. "More international students to head down under: report." The Sydney Morning Herald. Retrieved from http://www.smh.com.au

Underwood, J. and Szabo, A. 2003. "Academic offences and e-learning: individual propensities in cheating." British Journal of Educational Technology 34 (4):467477.

Jocoy, C., and DiBase, D. 2006. "Plagarism by Adult Learners Online: A case study in detection and remediation." International Journal of Research in Open and Distance Learning 7 (1): 1-15.

Jones, I. 2009. "Cyber plagarism: Different method - same song." Journal of Legal, Ethical and Regulatory Issues 12 (1):89 - 100.

Julius, A. 1998. "William Shakespeare, you stand accused of being a crow, and ape and a thief. How do you plead?" New Statesman 127 (4385):40-42.

Kent, C.and Salim, N. 2009. "Web Based Cross Language Plagarism Detection." Journal of Computing 1 (1):2151 - 9617.

King, M.L.Jr. 2004. 'I Have a Dream'. New African 435: 1.

Koshy, S. 2008. "A case of miscommunication? Obsticles to the effective implementation of a plagarism detection system in a multicultural university." Working Paper Series, Discipline: Management / Education 76 (2009), Dubai, University of Wollongong. 
Lancaster, T., and Culwin, F. 2007. "Preserving academic integrity-fighting against nonoriginality agencies." British Journal of Educational Technology. 38 (1):153-157.

Lea, M., and Jones, S. 2010. "Digital literacies in higher education: exploring textual and technological practice." Studies in higher education 36 (4):377-393. doi: 10.1080/03075071003664021.

Lessig, L. 2004. Free Culture. How big media uses technology and the law to lock down culture and control creativity. New York, NY: The Penguin Press.

Maurer, H., and Zaka, B. 2007. "Plagiarism - a problem and how to fight it." In Proceedings of World Conference on Educational Multimedia, Hypermedia and Telecommunications 2007, edited by Montgomerie, C. and Seale, J, 4451-4458. Chesapeake, VA: Association for the Advancement of Computing in Education McCabe, D., Klebe Trevino, L., and Butterfield, K. 2001. "Cheating in Academic Institutions: A Decade of Research." Ethics \& Behavior 11 (3):219-232.

McKeever, L. 2006. "Online plagiarism detection services—saviour or scourge?" Assessment \& Evaluation in Higher Education 31 (2):155-165.

Mirow, M., and Shore, P. 1997. "Plagiarism and Textual Ownership in the Digital Source Environment." Proteus-Shippensburg 14:41-43.

Park, C. 2003. "In Other (People's) Words: plagiarism by university students--literature and lessons." Assessment \& Evaluation in Higher Education 28 (5):471-488.

Park, C. 2004. "Rebels without a clause: towards an institutional framework for dealing with plagiarism by students." Journal of Further and Higher Education 28 (3):291-306.

Potthast, M., Barron-Cedeño, A., Stein, B., and Rosso, P. 2011. "Cross - language plagiarism detection." Language Resources and Evaluation 45, 45-62.

Selwyn, N. 2008. "'Not necessarily a bad thing ...': a study of online plagiarism amongst undergraduate students." Assessment \& Evaluation in Higher Education 33 (5):465-479.

Sharman, J., and Wilshire, C. 2007. "Fighting Plagiarism in Australian Universities: Why Bother?" Australian Journal of Political Science 42 (3):503-508.

Simon, C., Carr, J., Mccullough, S., Morgan, S., Oleson, T., and Ressel, M. 2004. "Gender, student perceptions, institutional commitments and academic dishonesty: who reports in academic dishonesty cases?" Assessment \& Evaluation in Higher Education 29 (1):75-90. 
Stamatatos, E., and Koppel, M. 2011. "Plagarism and Authorship Analysis: introduction to the special issue." Language Resources and Evaluation 45: 1-4.

Sterngold, A. 2004. "Confronting Plagarism: How conventional teaching invites cyber cheating." Change 36 (3):16 - 21.

Sutherland-Smith, W. 2010. "Retribution, deterrence and reform: the dilemmas of plagiarism management in universities." Journal of Higher Education Policy and Management 32 (1):5-16.

Thomas, M. 2000. "Eschewing credit: Heywood, Shakespeare, and plagiarism before copyright." New Literary History 31 (2):277-293.

Walker, J. 1998. "Student Plagiarism in Universities: What are we Doing About it?" Higher Education Research \& Development 17 (1):89-106.

Weingarten, K. and Frost, C. 2011. "Authoring Wikis: Rethinking Authorship through Digital Collaboration." The Radical Teacher 90, 47-57.

Williams, J. 2005. "Plagiarism: Deterrence, Detection and Prevention." In The Handbook for Economics Lecturers, 1-19. Bristol: The Higher Education Academy Economics Network. 